near the disc, attaining their normal size peripherally; the lower branch of the central artery pulsated on pressure, while the upper did not; the veins were all engorged with the exception of the superior nasal. There were no haemorrhages, and the macula was normal. Central vision was poor, especially for colours, and was reduced to counting fingers at 12 inches; with a $+5.0 \mathrm{D}$.Sph., fingers were counted at 1 metre; projection was accurate. The field of vision was full, and the blind spot showed only slight horizontal enlargement. No extraocular disease was found by the neurological and other departments, with the exception that there was some pyorrhoea; the mouth was, however, satisfactory after scaling and treatment.

Treatment consisted in local dry heat, and hot air baths, atropine, and iodides. The patient complained of right earache on the 16th which responded to simple treatment.

On the 22nd there was less swelling of the disc, and all the vessels pulsated on pressure; fingers were counted at 2 feet (unaided). On the 31st there was no measurable swelling, and vision, with the aid now of a $+6.0 \mathrm{D}$.S. had improved to $6 / 9$. The patient was discharged on December 7 to a Convalescent Home, vision being still as above; there was slight pallor of the disc, with blurring of its margins. On her return on December 27 vision was still $6 / 9$; the disc appeared normal, and the visual field was full. No change has since been noted.

The possibility of the involvement of the second eye being pure coincidence in each of the above cases must be at once admitted: but in case this were not so, it would be of considerable interest if these notes brought to light any similar cases hitherto unrecorded.

I am indebted to the honorary surgeons concerned, Sir John Parsons and Mr. Frank Juler, for their permission to report these cases.

NOTE ON THE CONTINUOUS EMPLOYMENT OVER A PERIOD OF YEARS OF SOLID ATROPINE AND COCAINE FOR CHILDREN'S REFRACTION

BY

\title{
ERNEST THOMSON
}

STIRLING

THE continuous employment of one method of doing anything, over a period of years and a large number of cases, furnishes not only a mass of statistics if one cares to extract these, but also gives a general impression of the value of the method, which is perhaps even more useful than bald figures. During the fourteen years 
of my connection with the Education Authority of the County of Lanark only one routine method of cycloplegia has been employed, that by means of the Ophthalmic Tabloid B. (B. W. \& Co.). This tabloid contains atropine hydrobromide $1 / 200 \mathrm{gr}$. and cocaine hydrochloride $1 / 200$ gr. During the period named I have examined the refraction of some 10,000 children; the exact figures are immaterial. Since the end of the war the Authority has employed other oculists besides myself and the same method has been employed continuously by these colleagues with, I am given to understand, complete satisfaction. Thus the material upon which to found an opinion is at least considerable.

The use of atropine tabloids was reported on by Moxon in 1913 (Lancet, October 11). When appointed oculist to the Education Authority (or, as it was then, the Secondary Education Committee of the County of Lanark) in 1914, that is in the earlier days of school medical treatment, I decided to give a trial to the method and selected the atropine and cocaine combination. It has been used exclusively ever since, although, should the accommodation not be paralysed in 1 to $1 \frac{1}{2}$ hours, atropine ointment is usually given for home use, the ointment being omitted on the morning of the second examination, when a tabloid is again applied.* As one would expect, considering the preponderating number of astigmatic cases that are sent to the school oculist, the tabloid is not effective every time any more than a single drop of atropine solution would be. To obtain exact numbers from the case-books would be too laborious and not worth while, but, thinking back, I would say that, assuming a dozen cases, the greater number astigmatic or presenting high errors, one case on an average might require further atropine. The method is simple to use, it is clean and, within the limits set by the flow of tears, exact. No doubt it is somewhat more expensive than solution, but it must be remembered that solutions require renewal, or at any rate sterilization, that they are less exact, and that they are more wasteful. Greasy preparations are unsatisfactory for refraction within an hour or so, on account of the film of grease on the cornea. There are various simple methods of applying the tabloid. Personally I think the butt end of a clean pen nib is as good as anything. One nurse became extraordinarily expert in taking up the tabloid in her fingers and inserting it before the child had the least idea of anything being done. The average individual would find difficulty in doing this and in any case it is not an ideal procedure. Moxon, if recollection serves, described a method of simultaneous binocular application, but nowadays the British child is so accustomed to doctors and nurses that only very

* It is worth noting that a full hour at least is required before attempting the retinoscopy, a fact which is perhaps against the single application method, in either solid or liquid form, in private practice. 
seldom is there any serious disturbance of the equilibrium or inconvenient flow of tears. Even the youngest are usually quite heroic unless by any mischance the oculist be mistaken for the dentist. Even the school dentist does not now encounter so much opposition as formerly.

I have no recollection of any case in which the total dose of $1 / 100 \mathrm{gr}$. of each drug caused inconvenient symptoms, though a slight dryness of the mouth is not uncommon. Nor to my recollection has any parent complained that the child had been affected after leaving the clinic. At times a child will suddenly turn faint immediately after the application, but that is due to " nerves" not to the drug. The drug is not used should a child seem to be unwell. Children are not allowed to return to school on the day they have atropine. A second tabloid is not applied on the same day, should one tabloid be ineffective. I have never forgotten an episode at out-patients at hospital a good many years since. My colleague had used scopolamine for refraction in an adult working man. As it happened, said colleague was called away, leaving his patients to me, and eventually I was obliged personally to conduct this hefty labourer, giddy and staggering, to the lavatory-and stand by.

There is one other point to which reference may be made. It has happened now and then that a series of cases on one day would prove refractory to the tabloid, and it almost seemed as if some particular tube contained tabloids of less potency than usual. On the other hand it might be pure coincidence. Messrs. Burroughs, Wellcome \& Co. assured me that the dosage was constant. But there is reason to suppose, with all due deference to this great firm, that it is possible to have samples of atropine of varying potency. In an article in the Lancet I had read about this, but neither the title nor the name of the author would come to mind. Neither Messrs. Burroughs, Wellcome \& Co. nor the editor of the Lancet, nor readers of the British Journal of Ophthalmology, of whom I made enquiry in 1923, led me to it, yet recently in that most informative book the Extra Pharmacopoeia of Martindale and Westcott I found a reference which seems to be the one sought. It is by H. R. Jensen (Lancet, ii, 1916, p. 797). Here is the quotation :"Atropine is to all intents an intimate mechanical mixture of $\mathrm{d}$ - and 1-hyoscyamines (i.e., dextrorotatory and laevorotatory) which differ in physiological effect. The purest atropine contains these two constituents in almost precisely equal quantities. This is not the case in the solanaceous alkaloids. Cushny showed that $0.045 \mathrm{mgr}$. 1-hyoscyamine had the same optic effect as $0.55 \mathrm{mgr}$. of d-hyoscyamine, hence the variety 1 . has twelve times the strength of the latter. A sample of Egyptian henbane (H. muticus) yielded at least 83 per cent. of its alkaloids as 1-hyoscyamine. 0.5 per cent. 
solutions of this are equal to 2 per cent. solutions of atropine for ophthalmic purposes." The Extra Pharmacopoeia states that while prior to the war atropine was derived from Central Europe it is now being made from Egyptian henbane in this country in larger quantities. From all this it seems clear that mistakes are possible, but since no overdosage has ever been suspected in the B. W. preparation it seems much more likely that the dosage is completely standardised and that the occasional run of failures is merely coincidental.

\section{ABSTRACTS}

\section{I.-TUMOURS}

(I) Barletta, Vincenzo (Catania). - The value of raised intraocular tension in the differential diagnosis betweeh glioma and pseudoglioma. (L'Ipertensione del bulbo nella diagnosi differenziale tra Glioma e Pseudoglioma.) Ann.di Ottal. e Clin. Ocul., Year LVII, p. 66, 1929.

(1) While it is usual to find that cases of glioma have raised tension, and cases of pseudoglioma are hypotonic, or tend to become so, the rule is not an absolute one and Barletta describes a case in which in a true glioma the tension in the early stages fell as low as $12 \mathrm{~mm}$. $\mathrm{Hg}$. In the later stages, the tension was raised. In discussing the possible causes of this lowered tension, he admits the possibility of detachment, but suggests also, that there may be atrophy of the iris and ciliary body and consequent diminution of aqueous secretion.

Leslie Patón.

(2) Schuster, E. (Königsberg).-A case of psammoma. (Ein Fall von Psammom.) Zeitschr. f. Augenheilk., Bd. LXIII, S. 65, 1928.

(2) Schuster describes a case of psammoma of the optic nerve occurring in a man aged 20 years. The ophthalmoscopic appearance was that of complete optic atrophy with chalky white discs and thin or partially obliterated arteries; there was also the appearance of retinal pigmentation characteristic of old chorioretinitis. There was a history of a slow and gradual loss of vision. $\mathrm{X}$-ray photographs of the optic nerve showed the presence of a well-differentiated granular shadow with a sharp outline; on the appearance of this shadow with its clear-cut characteristic nature, a diagnosis of psammoma was made, which was confirmed on subsequent histological examination. 